\title{
CRITICAL VIEWS ON SOME CHANGES AND SOME SUPPLEMENTS ON LAW NO. 273/2004 REGARDING THE ADOPTION PROCEDURE THROUGH LAW NO. $57 / 2016$
}

\author{
Teodora DRĂGHICI*, Teodor BODOAȘCĂ**, \\ Ioana-Raluca TONCEAN-LUIERAN** \\ *“Nicolae Bălcescu" Land Forces Academy, Sibiu, Romania, \\ **“Dimitrie Cantemir" University, Tîrgu-Mureș, Romania \\ teodora24a@yahoo.com, bodoasca_teodor@yahoo.com,tonceanioana@yahoo.com
}

\begin{abstract}
Recently, Law no. 57/2016 was adopted amending and supplementing Law No. 273/2004 regarding the adoption procedure and other legal acts. Contrary to Law no. 273/2004, Law no. 57/2016 has modified and supplemented what numerous aspects are concerned, not only the "adoption procedure", but also its "main conditions" and its "effects". Even if it seems a minor issue, we are still witnessing a case of non-compliance with the legislative technique for drafting laws. Basically, what Law no. 273/2004 is concerned, the "subject of regulation" has become incompatible with its "name", contrary to the regulations of art. 41 para. (1) of Law 24/2000 on legal techniques for drafting laws. Law no. 273/2004 has also been modified and massively completed, resulting a really long legal document, incomprehensible by those whom it concerns, difficult of being discussed and moreover difficult of being implemented by the authorities. To these aspects there are other contextual ones to be added, determined by the doubtful "logical legal fundament" of the amendments and additions as well as the modest concerns for correlations between the legal dispositions of Law no. 273/2004 and other legal provisions. Finally, numerous changes and additions to Law no. 273/2004 are of "obvious banality" questioning their practical "necessity and utility".
\end{abstract}

Keywords: rules of legal technique, logical and legal justification, fundamental conditions of the adoption, consent to adoption.

1. Amendments to the Title of Chapter II of Law no. 273/2004 regarding the adoption procedure

According to art.1 pt. 1 of Law no. $57 / 2016$, the Title of Chapter no. II is being modified and will be read as follows: "Fundamental conditions and conditions regarding the adoption consent" [1]. We mention that prior to this amendment Chapter II from Law 273/2004 was entitled "The fundamental conditions of adoption"'[2].

In our opinion, for the following reasons this "amendment" is "useless" in contradiction with the regulations of the legal technique for drafting laws and even with the Romanian grammar rules.

First of all, Chapter II from Law no. 273/2004 has been "renamed"' evidently ignoring the title of Law no. 273/2004 ("regarding the adoption procedure"). Contextually, we specify that after the $1^{\text {st }}$ of October 2011, "the fundamental conditions of the adoption" are regulated by the Civil Code (art. 455-468), therefore Law no. $273 / 2004$, according to its title, should regulate only the matters referring to "the adoption procedure". 
Secondly, in relation to the legal techniques for drafting laws, the expression "Title of Chapter II" (o.o. - T.B., T.D., I.T.) is faulty, creating confusion between the "structural elements" of the legal documents and their "titles".

Thus, under art. 51 para (3) from Law no. 24/2000 "Within the structure provided in para. (1), the article can be grouped into chapters that can be divided into sections and these last ones, if necessary, into paragraphs (thesis 1). Moreover, according to art. 51 para. (1) from Law no. 24/2010, the content of the legal document can be resumed in the summarised ideas: general dispositions or principles (let. a); dispositions regarding the fundamental regulation (let. b); transitional (let. c). "In the case of Codes and highly credible laws, the chapters can be grouped in descending order - in titles and, if necessary, in parts that can be books, this division is made in accordance with the organic link between the laws that they include" (II ${ }^{\text {nd }}$ thesis) (o.o. - T.B., T.D., I.T.). Finally, "the title" and the "chapter" are "structural elements" of the legal document, the first one being a "division" of the last.

Furthermore, according to art. 56 para. (2) from Law no. $24 / 2000$ "the titles, the chapters and the sections are defined by the synthetic expression that they set out" [3] (o.o. - T.B., T.D., I.T.). Paradoxically, even Law no. 24/2000 comprises regulations under which, in a clearly inconsistent manner the term of "denomination" is used as an element of the "title" of the legal documents. In this regard see for example art. 41 para. (1). Thus the "title of the legal document contains the generic name of the document according to its legal category and the issuing authority along with the subject to regulation expressed synthetically" (o.o. - T.B., T.D., I.T.).

Therefore, in "legal language", contrary to the meaning in the modern Romanian language, the notion of "title" should not include the meaning of "name" but only that of "structural element" along with "chapter" and "section". In the modern Romanian language, the notion of "title" can also mean "a word or text placed in front of an essay or in front one of its distinct parts, indicating briefly or suggestively its content" [4].

In this context, we specify that under art.37 para. (2) from Law no. 24/2000, "if a concept or term is not well established or can have different meanings, its meaning is set by the legal document that establishes it, ....., and becomes compulsory to the legal documents from the same field" (o.o. T.B., T.D., I.T.). Synthetically said, the usage of the "legal significance" of different terms or phrases is not optional but compulsory even for the legislator.

Thirdly, even if the new denomination of the $I^{\text {nd }}$ Chapter refers to "fundamental conditions" and "conditions regarding consent", grammatically the notion of "adoption" is linked only to the last conditions. Basically, as a result of this change, from a legal point of view, the expression "fundamental conditions" has become generic and obviously "asymmetric" as compared to the expression "conditions regarding the consent to adoption".

Fourthly, adding to the "denomination" the expression "conditions regarding the consent of adoption", it provides a "pleonastic meaning". Thus, "the consent to adoption" is mentioned both explicitly and implicitly when referring to the "fundamental conditions". In fact, the pleonastic expression is emphasized by the repetition of the notion "conditions".

Fifthly, this baffling change can suggest the idea that only "the consent to adoption" is subject to some particular legal requirements. In fact, the analysis of the dispositions from Law no. 273/2004 and of the Civil Code depicts that explicitly or implicitly every fundamental condition implies some special legal requirements. Considering the above, we suggest that the 
legislator, according to ferenda law, returns to the previous denomination of Chapter II (the fundamental conditions of adoption).

\section{Incompatible acts with the adopter}

Pursuant to art. 1 pt. 2 from Law no. 57/2016, art. 7 para. (2) from Law no. $273 / 2004$ has been modified, worded as follows "the person who has been permanently convicted for committing intentionally an offence against a person or family, and also for the crime of child pornography or drug traffic, cannot adopt".

Compared with the previous regulation, there where introduced offences such as "child pornography" and "traffic of predecessors", instead "the illicit consumption of drugs" has been removed. Referring to the addition of the two crimes, we consider that the legislature, instead of "adding to the previous list", should have "thought of" and "adopted" a generic and "comprehensive regulatory solution" that insures even in these circumstances, "stability over time" of Law no. 273/2004.

Indeed, the rules that contain "exhaustive citations", even if it mostly eliminates the possibility of different interpretations, in time becoming "incomplete", generate "legislative events". According to art. 57 para. (1) from Law no. 24/2000, there are some "legal events" such as "modifying", "completing", "abolishment" and "republishing" the legal documents.

It is also factual that the great frequency of legal events is likely to transform the legal norms from "legal regulations of social order" into "reasons for overturning the legal relations".

In this case, it is easy to understand that "intentionally committing any offence" underlines a reprehensible social behaviour which might affect the principle of "higher interest of the child" mentioned in many texts of Law no. 273/2004 [5]. Moreover, even Law no. 273/2004 gives us "nominative examples" where issues that do not underline any "social danger" exclude the quality of the adopter. We take into account, for example, the lack of "parenting skills", the "financial status" and also the inadequate "psychological characteristics" of the adopter or the adoptive family evoqued also by art. 16 para. (1) and (2) from Law no. 273/2004.

Instead, the "elimination of illicit drug consumption", from this enumeration, was determined most probably because of the fact that art. 2-9 from Law no. 143/2000 that refers to preventing and stopping the traffic and illicit drug consumption, the Civil Code or other non-criminal laws simply do not consider this act as a crime.

However, in an unjustified manner art. 1 pt. 2 from Law no. 57/2016, refers exclusively to "drug trafficking" being omitted the "predecessor trafficking" explicitly criminalised by art. 2-9 from Law no. 143/2000. Indeed, art. 2-9, being part of Chapter 2 , can be found under the name "Sanctions of trafficking and other illicit operations that involve substances under national control". According to art. 1 let. a) thesis I from Law no. 143/2000, are considered "substances under national control, drugs and predecessors, from tables - apendix no. I- IV".

Moreover, the "intent" requirement refers only to crimes committed against "the person" or "family". Indeed, this requirement is mentioned only after listing the two "categories of offence" and before crimes such as child pornography, drug trafficking and predecessor trafficking. Per a contrario, the analysed text is incident, even in the case where the two categories of crimes are committed with "fault". Basically, from this perspective the text from art, 7 para. (1) found in Law no. 273/2004 became "asymmetric".

However, for the same reasons, these restrictive requirements of committing a deed with "intent" is also applicable in the case of these crimes. Indeed, unlike the intent, "negligence" and "recklessness" as crimes [6], do not mean "bad faith". 
Finally, the analysed interdiction is in fact an "exception" from the "rehabilitation effects". Indeed, in common law according to Title IV from the General part of the Penal Code, rehabilitation "removes the effects of conviction". According to the presented observations, we suggest the legislature of ferenda law, that he modifies art, 7 para. (1) from Law no. 273/2004 so that "The person who has been permanently convicted for committing a crime intentionally, could not adopt".

\section{Amendments and supplements to the consent of adoption}

3.1. The absence of the natural parents or of the guardian to the two fixed terms for consent

Art. 1 pt. 3 from Law no. 57/2016 has modified art. 8 para. (2) from Law no. $273 / 2004$, meaning that it can be considered a wrongful refusal to consent to the adoption even if "in the case when, although duly summoned the natural parents or, where appropriate, the guardian is not present at the two fixed terms for consent". We mention that in the old document, this text sets up the condition that the natural parents or the child's guardian "repeatedly" be absent to the fixed terms for consent.

However, in our opinion, the provisions from art. 8 para. (2) from Law no. $273 / 2004$, as "amended", suppose some particular observations.

First of all, most likely, this radical solution is circumscribed to the requirements of principle "speed in performing any acts related to the adoption procedure" provided by art.1 lit. e) from Law no. 273/2004.

Secondly, unjustified, although the "adoptive parent" is in this situation as the "natural parent" (when she has to consent with her husband to the adoption of the child) he is not subject for this restriction. Indeed, according to the Civil Code, on the one hand, "the married person who has adopted a child must consent to the adoption of the same child, by her husband" [art. 464 para. (3) thesis I] and on the other hand, "the adopter has towards the adopted child the rights and duties of a parent towards his natural child" (art. 471). Obviously, from this perspective, the provisions of art.8 para. (2) from Law no. $273 / 2004$ are unconstitutional, because they disregard the principle of equality before the law, without privileges or discriminations as stated in art. 16 para. (1) from the Constitution. In this case, the one discriminated by the legislature is the "natural parent" of the child.

Thirdly, given the fact that the analysed text makes no distinction about the justified or unjustified absence, we should accept that this is an incident in every possible situation including when the absence to the legal fixed term is "incidental". However, one can't ignore the fact that we are witnesses of a "wrongful refusal presumption", in lack of evidence that can suggest otherwise, as stated in art. 32 para. (2) C civ.pr. Otherwise, in an obvious inadmissible manner, the "natural" parent would be "sanctioned", even when acting without guilt (incidental), thus being defeated the general principle of the right and of "justice".

Fourthly, unlike the old regulation, where there was set a condition regarding the "repeated" absence, now it is limited to only two terms. In this context, we observe that this text does not speak about "successive" terms. As a result, it is considered incident even the situation where the second "absence" is preceded by one or more "presences" at the hearings.

Fifthly, applying this text also in the case of the "guardian" is because of the "legislatures tendency" to plea under the sign of identity the rights and duties of the parents and of the child's guardian. This solution is absolutely natural because guardianship, adoption and special protection measures are elements of "alternative protection". Therefore, according to art. 44 from Law no. 272/2004 
on the promotion and protection of the child rights, "any child who is temporarily or permanently deprived of parental protection, or the child can't be left in their care for his own good, is entitled to alternative protection (para. (1)) [7]. The protection mentioned in para. (1) includes establishing guardianship, the special protection measures stipulated by the law and adoption (para. (2) thesis I) (o.o. - T.B., T.D., I.T.). Basically, according to the legal order of preference, among the alternative forms of child protection, "establishing guardianship" is a priority.

Sixthly, art.8 para. (2) from Law no. $272 / 2004$ referring exclusively to the "guardian" is somewhat unrelated to art. 112 para. (1) and urm. $\mathrm{C}$ civ. as it regulates only the situation when the guardian is a "single physical persona". Therefore, on the basis of this text, "may be a natural guardian a physical persona or the husband and wife together" (o.o. - T.B., T.D., I.T.).

Seventhly, we notice the "dispositive" formulation of art. 8 para. (2) from Law no. $273 / 2004$, which means that even if the natural parent or the legal guardian was not present at two hearings, at which he was summoned, the court is entitled to decide that it is not the case of a "wrongful refusal to consent to the adoption". The court may decide in this regard especially in the situation where the absence to the legal hearings is not the "natural parent" or the "guardians" fault.

Eighthly, even if the analysed text refers generically to these "terms", these are legal terms. This explanation is imposed to avoid different interpretations, because during the procedure of adoption, the involved people in this matter, are called also by other authorities. These observations are also necessary, so that the provisions from para. (2) be in accordance with para.(1) of art.8 Law no. 273/2004.

Regarding the presented information, we suggest to the legislature, as ferenda law, to amend the provisions of art. 8 para. (2), Law no. $273 / 2004$ so that it could consider wrongful refusal to consent to an adoption, also the case when, even though legally summoned the natural parents, the adoptive parents or if the case requires it the legal guardian(s), without any reason do not show up to the two fixed legal terms set for consent to the adoption.

\subsection{Additions on the consent to adoption by the biological parents/the child's guardian}

As stated in art. 1 pt. 4 from Law no. 57/2016, para. (2) from art. 8 Law no. $273 / 2004$, there have been added 4 new paragraphs and new articles covering various aspects regarding the adoption consent of the natural parents/guardian of the child.

\subsubsection{Prohibiting expression of consent by other persons instead of biological parents}

Concretely, according to art.8 para. (3), Law no. 8/1996 the consent to adoption can't be expressed for the natural parents/guardian of the child by the trustee, nominee or other person, even empowered in this regard.

By establishing this text, probably, it was desired to impose the direct expression of consent to adoption by the biological parents or guardians of the child, in accordance with the requirements of the "immediate principle" [8].

However, art.8 para (2) from Law no. 273/2004 prohibits expressis verbis with "another person" as the "curator" or the "trustee" to consent to the adoption "in the place of the legal parents/legal guardian".

Obviously, between "consenting to" and "consenting for" another person can't be an equivalence. In the first case we witness the "representation" of a person and in the second "substitution in right" of another person.

Because of the fact that the role of the "curator" and the "trustee", is especially of representation, we can conclude that really, introducing this text meant, in terms of natural parental/guardian consent, that it will be expressed "personally" by the ones 
mentioned, or in other words, that the representation be excluded.

By substituting the parents/guardian, it can't be possible as art. 463 para. (1) let. a) $\mathrm{C}$ civ. firmly states that in order to adopt "it is necessary that the natural parents, or if the case requires it the legal guardian, give their consent".

Referring to those underlined above, we suggest the legislator that, by ferenda law, he modifies the provisions of art. 8 para. (3) from Law no. 8/2004, by replacing the expression "replacing the natural parents/guardian" with "for the natural parents/guardian".

\subsubsection{Consent when missing the parent}

According to art. 8 para. (4) of Law no. $273 / 2004$, introduced by art. I pt. 4 of Law no. 57/2004 "exceptionally in the case where one of the natural parents, even if there have been made the necessary steps, could not been found to consent, the consent of the other parent is sufficient". (thesis I) When both of the parents are in this situation, the adoption can't be finalised (II ${ }^{\text {nd }}$ thesis).

This completion of art. 8 of Law no. $273 / 2004$ is exclusively incident when the child is under "parental care". The reproduced text refers exclusively to "one of the parents" (thesis I) respectively to "both parents" (II ${ }^{\text {nd }}$ thesis), ignoring the "guardian".

In the case of the parents or parent that could not be "found", the declaration of adoption without their consent acts like a veritable "sanction" of the family right.

In this context, we underline the "exceptional feature" of the adoption finalisation without the consent of one or both of the natural parents, circumstance that requires the court to determine the "real reasons" because of which the parent or the parents could not be found and especially if these reasons are attributed to them.

If the trusteeship has been instituted towards the child, the fact that the guardian or the guardians could not be found consists a persistent reason, to eliminate the guardian (from the guardianship) according to art. $158 \mathrm{C}$ civ. and appoint another guardian.

Also, we observe that the analysed text refers only to the parent and the natural parents, what means that per a contrario, this is not applicable in the case of the "adoptive parents". As in the previous case, we are witnesses to an unconstitutional rule opposite to the principle underlined by art. 7 para. (1) of the Constitution.

Finally, pursuant to art 1 pt. 6 of Law no. 57/2016, after art. 9 of Law no. 273/2004, there has been added a new article, art. 91, as follows: "The Directorate in which jurisdiction the child lives, has the obligation to issue a report of the performances made for finding the natural parent" (thesis I). "This report shall be attached to the demand to open the adoption procedure" (II nd thesis). "Directorate" has the following meaning General Directorate of Social Assistance and Child protection.

Even if the provided text does not stipulate it explicitly, it can be understood that the steps for finding the natural parents of the child are followed by the Directorate where the child lives. However, if the child does not reside at his parents this solution is irrational. In our opinion, because of the fact that those who we look for are the parents of the child, this person being often individualised on a certain territory by "residence", a rational solution would have been that the steps in finding the parents and the report, be made by the Directorate where their home is.

\subsubsection{Consent through a delegated judge}

According to art. 8 para. (5) from Law no. 273/2004 "The court may approve taking consent from the home of the one cited to express his consent, through a delegated judge, if the cited one, because of solid reasons, is prevented to appear in front of the court".

From our point of view, this text requires some particular and critical observations. 
First of all, per a contrario interpretation, this text is not applicable in the case where "the one cited to express his consent" is to be found "in another place" than "his residence" such as a hospital or in a place of detention. Obviously, to eliminate this "restrictive effect" the text of art. 8 para. (5) from Law no. 273/2004, should be modified by replacing the term "residence" with the phrase "where he can be found".

Secondly, because of the vague expression on what the "place" where his home can be found, this can be located in the country or abroad. The "home" can also be the domicile or the residence of this person.

Thirdly, the analysed text refers generically to "the one cited to express consent" what means that it refers to all the people cited to consent to the adoption [9], not just natural parents/guardian according to the classical principle ubi lex non distinguit, nec nos distinguere debemus. However, para. (5) is in an obvious disagreement with para. (1) - (4) that refers exclusively to the "natural parents" and the "guardian" of the child. In this regard, consciously or not, the legislature is "inconsistent". Most probably we are witnesses to "negligence in expression" which by law ferenda should be remediated.

Fourthly, in extremis, art. 8 para. (5) from Law no. 273/2004, refers inadequately to the "part" which by solid reasons is prevented from presenting himself in front of the court. In this context, we mention that according to art. 74 para. (4) from Law no. $273 / 2004$, "the opening requirements of the internal adoption procedure, child custody request for the adoption and the requirements for finalising the adoption, are being firstly judged according to rules stipulated in the III $^{\text {rd }}$ Book - General provisions regarding the non-contentious procedures of the Civil Procedures Code, along with the exception stipulated by this law (o.o. T.B., T.D., I.T.). Obviously, under the analysed terms, Law no. $273 / 2004$, does not establish any exception. Being in the presence of a "non-contentious procedure", the cited people are not "parties" as art. 8 para. (5) from Law no. 273/2004 wrongly stipulates. Thus, under art. 527 Civil Procedures Code, "The requests where the court has to intervene in order to find a solution, without willing to establish a contrary duty towards another person such as judiciary authorisations or taking legal measures of surveillance, protection or assurance, are subject to the provisions of this book" (o.o. - T.B., T.D., I.T.).

Fifthly, the expression "taking consent" with an imperative sense can generate ambiguity on what freedom of expression is concerned. Regarding these observations, we suggest that the legislature modifies art. 8 para. (5) from Law no. $273 / 2004$, resulting that "the court may approve consent at the place where the person can be found if for serious reasons, he is prevented to appear before it".

\subsubsection{Consent through derogatory comission}

Pursuant to article 8 para. (6) from Law no. 273/2004, introduced by art. I pt 4 from Law no. 57/2006 "the person who resides in the jurisdiction of another court according to the situation underlined in para. (5) consents by derogatory committee". In this case, we mention that in the common rules there are regulations regarding "the rogatory letters" only when talking about "evidence administration" according to art. $261 \mathrm{C}$ pr. civ.

\subsection{5. "Informing" or "explaining" about the consent}

According to art. I pt. 9 from Law no. $57 / 2016$, art. 9 from Law no. $273 / 2004$ has been amended and states: "the natural parents of the child or, if the case requires it, the legal guardian, must consent to the adoption freely and unconditionally, just before it has been explained to them in a comprehensible language, the consequences of expressing their consent and what the termination of the familiar link between the parents and the child following the 
declaration of adoption implies (thesis I). The obligation to provide advice and the necessary information, before expressing the consent to the adoption, lies with the direction, where the natural parents, or if the case requires it, the legal guardians live in, also creating a report in this case (II ${ }^{\text {nd }}$ thesis). This report is presented to the Directorate from the child's residence, in 15 days from its request (III ${ }^{\text {rd }}$ thesis).

Compared to the previous text, we find that thesis I and II have been modified and thesis III has been newly added.

In thesis I, instead of "informing" the natural parents, or if the case requires it, the legal guardian, they were "explained" in an adequate language the consequences of giving their consent and the termination of the family ties that it implies following the declaration of adoption. Generally, "informing" has the meaning of "making something familiar to someone" [10]. On the other hand, "explaining" refers to "giving specific details about something to someone" [11]. Basically, after "informing" the natural parents, or if the case requires it, the legal guardians, they are told about the consequences of finalising the adoption. On the other hand, the "explanation" aims at them understanding the consequences of this adoption.

In this context, we mention that the provisions from art.9 from Law no. $273 / 2004$, contrary to the rules of legal technique for drafting laws, doubles mainly the provisions of art. $465 \mathrm{C}$ civ. Indeed, according to them, the natural parents, or if the case requires it, the legal guardian, must consent to the adoption freely, unconditionally and only after being correctly informed about the consequences of adoption, especially after the termination of the family ties between the natural family and the child.

In the case of the $\mathrm{II}^{\text {nd }}$ thesis, the changes are only on what the "expression" is concerned, without consequences on the fundament of the legal solution. Basically, this change is not justified.

In our opinion, the newly introduced thesis III is contrary to the "celerity" principle. Indeed, this provision determines the extension of the adoption procedure with at least 15 "working days" that results in fact in 21 days. Moreover, the notion of 15 "working days" begins when the direction from the child's home asks for the directorates report.

In this situation, we consider it appropriate that, by law ferenda, this text be modified so that the period for the communication be shorter, possibly 10 days and the communication be an office one. Moreover, for the same reasons, thesis II should be modified as well so that the directorate from the region where the parents, or if the case requires it, the legal guardian lives, prepares the 'counselling and information report' faster.

\subsubsection{Consent when adopting a major person}

Finally, art. 1 pt.7 from Law no. 57/2016 has added art. 151 that states: "In the case of the adoption of a person who has acquired full legal capacity, the consent of the adopter or the adoptive family and that of the adopted one is expressed before the court" (first thesis)." Natural parental consent is not necessary" (second thesis).

In this context, we mention that the provisions of art. 151- second thesis from Law no. 273/2004 were present in its content, but most probably, by mistake, they were repealed by art 230 let. y) from Law no. 71/2011, without including in the Civil Code a corresponding provision.

\section{References}

[1] Law no. 57/2016 was published in the Official Gazette of Romania, First Part, no. 283 from 14th of April 2016. 
[2] Law no. 273/2004 was published in the Official Gazette of Romania, First Part, no. 557 from 23rd of June 2004 and republished in Official Gazette of Romania, First Part, no. 259 from $19^{\text {th }}$ of April 2012, later being amended.

[3] Law no. 24/2000 was published in the Official Gazette of Romania, First Part, no. 139 from 21st of March 2000 and republished in Official Gazette of Romania, First Part, no. 260 from 21st of April 2010, later being amended.

[4] Dictionary of Romanian Language (DEX) published by the Romanian Academy - Institute of Linguistics "Iorgu Iordan", Second Edition, Encyclopaedic Universe publishing house, Bucharest, Romania, pp. 1094, 1998.

[5] See for eg art.1 let. a), art 8 para. (1), art. 27, art. 29 para. (3) and art. 36 alin. (2) from Law no. $273 / 2004$.

[6] See art. 16 para. (3) Civile Code and art. 16 para. (4) Penal Code.

[7] Law no. 272/2004was published in the Official Gazette of Romania, First Part, no. 557 from 23rd of June 2004 and republished in Official Gazette of Romania, First Part, no.159, from 5 March 2014, later being amended.

[8] See art. 16 Civil Code of procedure.

[9] See art. 463 Civil Code.

[10] See DEX, pp. 491.

[11] See DEX, pp. 358. 